\title{
When is Sentinel Lymph Node Biopsy Useful in Ductal Carcinoma In Situ? The Experience at a Latin American Cancer Center
}

Sandra E. Diaz Casas ${ }^{1}$, Wilmar A. Serrano Muñoz ${ }^{2}$, Nelson A. Buelvas Gómez ${ }^{1}$, Ana M. Osorio Ruiz ${ }^{2}$, Javier Ángel Aristizábal ${ }^{1}$, Luis H. Guzmán Abisaab ${ }^{2}$, Mauricio Garcia Mora ${ }^{1}$, Carlos Lehmann Mosquera ${ }^{1}$, Sergio Cervera-Bonilla ${ }^{1}$, Ricardo Sanchez Pedraza ${ }^{3}$

1. Breast and Soft Tissue Surgery, Instituto Nacional de Cancerología, Bogotá D.C, COL 2. Breast Surgery, Instituto Nacional de Cancerología, Bogotá D.C, COL 3. Epidemiology and Public Health, Instituto Nacional de Cancerología, Bogotá D.C, COL

Corresponding author: Wilmar A. Serrano Muñoz, wilmarserrano82@hotmail.com

\section{Abstract}

\section{Introduction}

Ductal carcinoma in situ (DCIS) accounts for $15 \%$ of breast cancers. Surgery is the main treatment, and the use of sentinel node biopsy (SLNB) is restricted to patients at risk of infiltration, which is estimated to be around $26 \%$.

\section{Materials and methods}

Aimed at evaluating the benefit of SLNB in patients with DCIS at the Breast and Soft Tissue Functional Unit of the National Cancer Institute (INC for its initials in Spanish), a descriptive observational study of a retrospective cases series was conducted between August 1, 2013, and September 30, 2018.

\section{Results}

A total of 40 patients with a median age of 57 years were included in the study; $62.5 \%$ of them underwent mastectomy with SLNB, and the remaining 37.5\% underwent conservative surgery with SLNB. 100\% of sentinel nodes were identified, by using lymphoscintigraphy in $95 \%$. Sentinel node was positive in four patients (10\%), three of whom had infiltration in the surgical specimen reported. With a follow-up of 49 months, only one patient had a local relapse. None of the patients had axillary or distant recurrence.

\section{Conclusions}

SLNB in DCIS should be limited to patients with risk factors for infiltration (tumor size greater than $3 \mathrm{~cm}$, comedo-type histology, and high-grade DCIS), and patients with an indication for mastectomy. Its percentage of complications is low, and a high identification percentage in surgical groups with adequate training.

Review began 05/24/2021 Review ended 06/06/2021 Published 07/03/2021

\section{() Copyright 2021}

Diaz Casas et al. This is an open access article distributed under the terms of the Creative Commons Attribution License CC-BY 4.0., which permits unrestricted use, distribution, and reproduction in any medium, provided the original author and source are credited.
Categories: General Surgery, Oncology

Keywords: breast carcinoma in situ, ductal carcinoma in situ, sentinel node biopsy, axillary lymph nodes, lymph node metastases

\section{Introduction}

Breast cancer ranks first in incidence in women in the world. According to Global Cancer Incidence, Mortality, and Prevalence (GLOBOCAN) 2020 data, 2,261,419 new cases were diagnosed, which account for $11.7 \%$ of all cancers, and 684,996 deaths were recorded for both genders. In Colombia, breast cancer ranks first in incidence and third in mortality; for the same year 2020, a total of 15,509 new cases were reported, which accounts for $13.7 \%$ of the total cancers reported in the country [1]. Currently, ductal carcinoma in situ (DCIS) represents $15 \%$ of newly diagnosed breast cancer, and in most cases, diagnosis is incidentally made by finding microcalcifications during a screening mammogram [2].

The term breast carcinoma in situ is used to describe lesions of abnormal epithelial cells confined to the lobes or ducts of the breast, but similar in appearance to invasive carcinoma cells, without exceeding the basal membrane. It was argued for a long time that these cells could invade the adjacent breast stroma and eventually progress to invasive cancer. However, carcinoma in situ does not fully express several of the characteristics of invasive carcinoma, and the molecular changes involved in progression to invasive cancer do not always occur. [3,4]

Overall prognosis is good, with specific mortality of $3 \%$ at 15 years. In follow-up studies of patients with 
DCIS who did not undergo surgical resection, it was found that between $20 \%$ and $53 \%$ of patients were diagnosed with invasive breast cancer within the next 10 years, finding that invasive local recurrences can lead to distant metastases in $12 \%$ to $15 \%$ of cases $[2,5]$.

DCIS treatment is essentially surgical, ranging from conservative surgery to radical surgery depending on lesion extent. The use of sentinel node biopsy (SLNB) is restricted to patients at risk of infiltration, which is estimated to be around 26\% [6]. Although SLNB is a minor procedure with low morbidity rates, there is a $6 \%$ risk of developing lymphedema [7]. The meta-analysis carried out by Brennan et al. shows that the preoperative variables that significantly increase the risk of infiltration in DCIS are: use of thinner biopsy needles, tumors larger than $20 \mathrm{~mm}$, a palpable lesion, and mammography categorized as Breast Imaging Reporting and Database System (BI-RADS) IV or V [6]. The literature reports presence of metastatic positive nodes in patients with DCIS ranging from $2 \%$ to $15 \%$ [8-10].

Current guidelines recommend SLNB in patients with DCIS who require a mastectomy since no lymphatic vessels are left after radical surgery (they are excised in bloc with the rest of the fibroglandular breast tissue), and therefore an SLNB could not be performed in a subsequent surgery in case that pathology reports infiltration [11]. Other indications for SLNB in DCIS include tumor high suspicion of infiltration (tumors greater than $3 \mathrm{~cm}$ or a high histological grade, and presence of comedo necrosis pattern) [12], all of these factors increasing the rate of underestimating infiltrative disease. Based on these indications and despite the low probability of obtaining a positive SLN, SLNB in DCIS has become an increasingly common practice, so much so that it was performed in $19 \%$ of patients with DCIS undergoing breast-conservative surgery and in $63 \%$ of patients with DCIS undergoing mastectomy in the USA in 2012. [13].

Regarding the usefulness of SLNB in patients with DCIS who are undergoing breast-conserving surgery, two large studies have been recently reported. The first one was carried out by El Hage Chehade et al., who in 2017 published a meta-analysis evaluating 9,803 patients from 48 studies, recommending that SLNB could be safely omitted in DCIS smaller than $2 \mathrm{~cm}$ with a high histological grade, or in DCIS greater than $2 \mathrm{~cm}$ with low or intermediate histological grades [14]. In the second one in 2019, Hung et al. showed a study based on a SEER population with 1992 patients, with older adults in the age range of 67 and 94 years who were taken to breast conservative surgery (BCS) and SLNB, with no impact observed on locoregional recurrence or in general survival, suggesting the little benefit of SLNB in older patients with DCIS who undergo BCS [15].

The main objective of this work is to evaluate sentinel node performance in patients with DCIS who underwent surgical treatment at the Breast and Soft Tissue Functional Unit of the National Cancer Institute (INC for its initials in Spanish) between September 1, 2013 and August 31, 2018; percentage and type of complications derived from this surgical technique and tumor relapse.

\section{Materials And Methods}

A retrospective case series descriptive observational study was carried out between September 1, 2013 and August 31, 2018, which included all patients with a diagnosis of DCIS registered in the database of the Functional Breast and Soft Tissue Unit of the Nacional Cancer Institute, who underwent surgical management of the primary tumor and SLNB. The information was collected from data recorded in the INC's SAP ${ }^{\circledR}$ electronic medical records system (SAP AG, Walldorf, Germany). Information collection was recorded in a format designed with the study variables, which included demographic, histopathological, treatment, and follow-up information. Patient data were collected and recorded by three of the authors in an electronic database based on the REDCapTM platform (Vanderbilt University, Nashville, TN); data were later reviewed by the authors, and their quality was supervised by the monitoring center of INC research department. The Functional Unit has established to follow up the patients with DCIS every three months during the first two years and every six months between the second and fifth year and finally every year after the fifth year. The mammography is performed annually. In cases with follow-up loss, the patient or her relatives were contacted by telephone to verify whether or not the outcome related to disease-free survival had occurred.

Patients with a histological diagnosis of DCIS, who underwent surgical management of the primary tumor (radical surgery or BCS) and SLNB by one of the specialists of the Functional Breast and Soft Tissue Unit of the INC during the study period were included. Patients not undergoing axillary intervention were excluded, as well as patients with a diagnosis of infiltrating carcinoma in the pathology review, and those who were not managed at the institution.

Variables were analyzed by using conventional methods of descriptive statistics; categorical variables were summarized using absolute frequencies and percentages, and continuous variables were summarized using medians and interquartile ranges (IQR).

The statistical analysis of the information was carried out in the STATA 15.0 software licensed for the National Cancer Institute.

\section{Results}

A total of 1,682 patients diagnosed with breast cancer were admitted to the INC between September 1, 2013 


\section{Cureus}

and August 31, 2018; of these, 1,336 patients (79.4\%) had invasive cancer in early and locally advanced stages, 286 (17\%) were in metastatic stage (IV), and 60 patients (3.5\%) had to DCIS, which were candidates to be included in present study; 20 of them were excluded for the following reasons: three patients had an infiltrating component in the INC revision pathology, six did not accept surgical treatment, and 11 patients were treated only with breast surgery and no SLNB was performed. So, of these 60 patients, 40 met the study inclusion criteria and were entered for analysis (Figure 1).

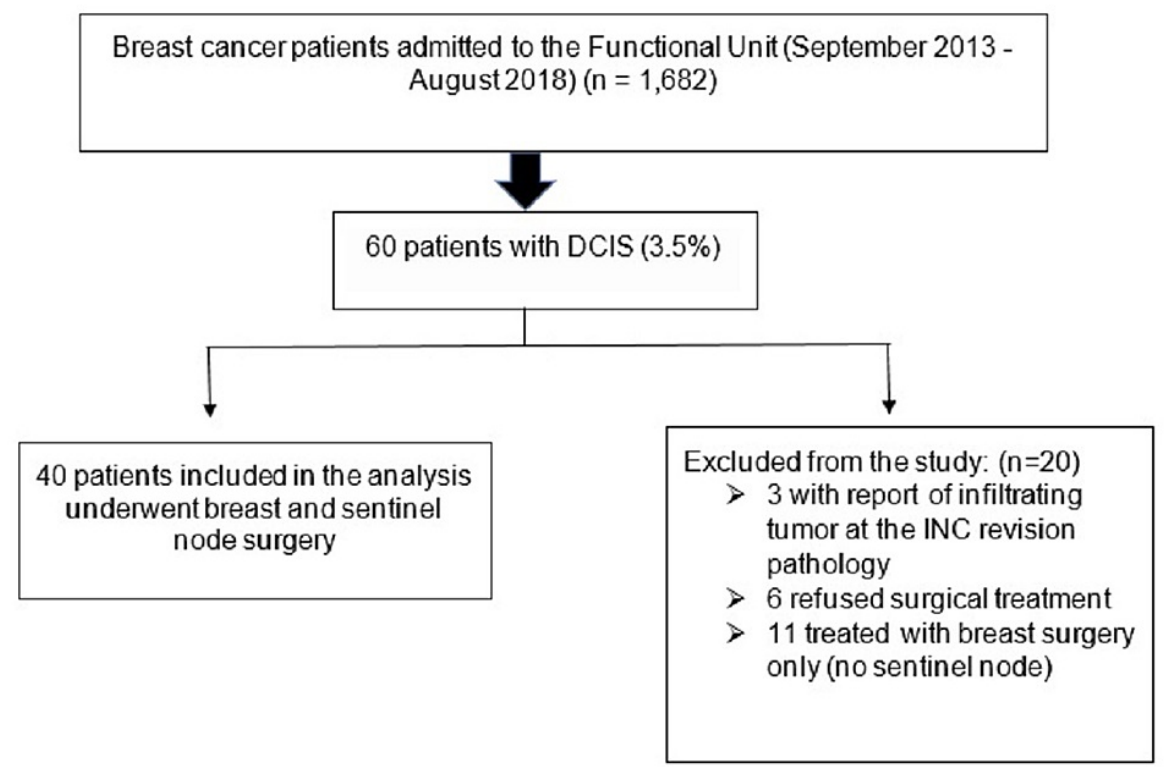

\section{FIGURE 1: Inclusion criteria}

The median age was 57 years (IQR $=13$ years), from 37 to 77 years. All patients were female. On physical examination, the tumor was palpable in $70 \%(n=28)$ of patients. In the biopsy pathology report, only $47.5 \%$ $(n=19)$ had a single histological type, and $53.5 \%(n=21)$ had a combination of 2 and 3 histological types. The predominant histological subtype was comedo in $57.5 \%(n=23) ; 65 \%(n=26)$ of the patients had histological grade III, and $67.5 \%(\mathrm{n}=27)$ were hormone receptor $(\mathrm{HR})$ positive. Table 1 shows the demographic and clinical characteristics of the patients. 


\section{Cureus}

\begin{tabular}{|c|c|c|}
\hline Characteristic & Number $(n=40)$ & Percentage (\%) \\
\hline Age: median (IQR) & $57.5(37-77)$ & \\
\hline Health scheme & $\mathrm{n}$ & $\%$ \\
\hline Contributory & 24 & 60 \\
\hline Subsidized & 16 & 40 \\
\hline Presence of palpable tumor & $\mathrm{n}$ & $\%$ \\
\hline Palpable tumor & 28 & 70 \\
\hline Non-palpable tumor & 12 & 30 \\
\hline Histological type (biopsy) $^{\star}$ & $\mathrm{n}$ & $\%$ \\
\hline Comedo & 23 & 57.5 \\
\hline Solid & 16 & 40 \\
\hline Papillary & 1 & 2.5 \\
\hline Micropapillary & 1 & 2.5 \\
\hline Cribriform & 12 & 30 \\
\hline No data & 6 & 15 \\
\hline Histological grade & $\mathrm{n}$ & $\%$ \\
\hline 1 & 1 & 2.5 \\
\hline 2 & 11 & 27.5 \\
\hline 3 & 26 & 65 \\
\hline No data & 2 & 5 \\
\hline Hormone receptors & $\mathrm{n}$ & $\%$ \\
\hline Negative & 10 & 25 \\
\hline Positive & 27 & 67.5 \\
\hline No data & 3 & 7.5 \\
\hline Ki 67 & $\mathrm{n}$ & $\%$ \\
\hline$\leq 20 \%$ & 3 & 7.5 \\
\hline$\geq 21 \%$ & 6 & 15 \\
\hline No data & 31 & 77.5 \\
\hline
\end{tabular}

\section{TABLE 1: Demographic and clinical characteristics of patients included in the study}

*21 Patients presented 2 or 3 histological types in the biopsy; the table reports the total number for each histological type, regardless of combinations.

Regarding surgical treatment of the primary tumor, $62.5 \%(n=25)$ of the patients underwent mastectomy, and $37.5 \%(n=15)$ underwent BCS. Indications for performing a SLNB were: mastectomy performed due to poor breast-tumor relationship and multicentricity in $60 \%(n=24)$; suspected infiltration in the initial biopsy $17.5 \%(n=7)$; ductal carcinoma in comedo-type situ in 55\% ( $n=22)$; high histological grade in $60 \%(n$ $=24$ ) of cases; and tumor size greater than $3 \mathrm{~cm}$ in one patient. Most of the patients had more than one indication $65 \%(n=26)$ for SLNB.

Sentinel node identification was achieved in 100\% of cases, using lymphoscintigraphy in 38 patients (95\%), and dual technique (lymphoscintigraphy + methylene blue) in two patients (5\%). Distribution of the number 


\section{Cureus}

of sentinel and non-sentinel nodes obtained during the procedure are summarized in Table 2 .

\begin{tabular}{|l|l|l|}
\hline Characteristic & Percentage (\%) & Number \\
\hline Type of surgical treatment of primary tumor & 62.5 & 25 \\
\hline Simple mastectomy & 37.5 & 15 \\
\hline Conservative surgery & & 38 \\
\hline Sentinel node identification technique & 95 & 2 \\
\hline Lymphoscintigraphy & 5 & 40 \\
\hline Dual technique & 100 & 22 \\
\hline Sentinel node identification percentage & & 13 \\
\hline Number of resected sentinel nodes & 55 & 5 \\
\hline 1 & 32.5 & 13 \\
\hline 2 & 12.5 & 3 \\
\hline 3 or more & 32.5 & 9 \\
\hline Patients with resected non-sentinel nodes. & & 3 \\
\hline Number of resected non-sentinel nodes & 69.23 & 2.69 \\
\hline 1 & 23.08 & 2 \\
\hline 3 or more & & 3 \\
\hline
\end{tabular}

\section{TABLE 2: Type of surgical treatment received by the patients of the study}

Regarding the pathology report of the surgical specimen, $7.5 \%(\mathrm{n}=3)$ of patients had margins $<2 \mathrm{~mm}$, and $12.5 \%(\mathrm{n}=5)$ had positive margins. Of the total eight patients with positive and close borders, five were taken to second surgery for margin clearance, mastectomy was made in one patient, and margin clearance was not performed in two patients due to non-acceptance of the procedure.

Sentinel node was positive in $10 \%(n=4)$ of patients, two of these were macrometastasis. All had palpable lesions of high histological grade; HR positive and infiltrating tumor in the surgical specimen was found in three of them.

None of the non-sentinel nodes assessed presented metastasis. As for patients with positive sentinel lymph nodes, axillary management with axillary dissection was performed in two of them, who were patients whose SLNB pathology reported macrometastasis; axillary dissection was omitted in the other two patients (Table 3). 


\section{Cureus}

\begin{tabular}{|c|c|c|}
\hline Characteristic & Number ( $n$ ) & Percentage (\%) \\
\hline \multicolumn{3}{|l|}{ Tumor size } \\
\hline$<1 \mathrm{~cm}$ & 7 & 17,5 \\
\hline $1-2 \mathrm{~cm}$ & 14 & 35 \\
\hline$>2 \mathrm{~cm}$ & 15 & 37,5 \\
\hline No data & 4 & 10 \\
\hline Mean primary tumor size $=2.38 \mathrm{~cm}$ & (IQR: 2,4) & \\
\hline In situ tumor histological type ${ }^{\star}$ & $\mathrm{n}$ & $\%$ \\
\hline Comedo & 20 & 50 \\
\hline Solid & 14 & 35 \\
\hline Papillary & 4 & 10 \\
\hline Micropapillary & 3 & 7.5 \\
\hline Cribriform & 14 & 35 \\
\hline No data & 8 & 20 \\
\hline \multicolumn{3}{|l|}{ Infiltration type } \\
\hline In situ & 19 & 47.5 \\
\hline Presence of infiltrating tumor & 21 & 52.5 \\
\hline Resection edges & $\mathrm{n}$ & $\%$ \\
\hline Free & 32 & 80 \\
\hline Close to $<2 \mathrm{~mm}$ & 3 & 7.5 \\
\hline Positive & 5 & 12.5 \\
\hline Sentinel node positive patients & 4 & 10 \\
\hline Type of sentinel node metastatic involvement & $\mathrm{n}$ & $\%$ \\
\hline Single tumor cells or small clusters & 1 & 2 \\
\hline Micrometastases & 1 & 2 \\
\hline Macrometastases & 2 & 5 \\
\hline
\end{tabular}

\section{TABLE 3: Anatomopathological features of the surgical specimen of the primary tumor and the}

sentinel node

* 25 pathologies report more than one histological type.

$53.5 \%(n=21)$ of patients had an infiltrating tumor in the final pathology report, 10 of them with tumor size greater than $2 \mathrm{~cm}, 11$ patients with comedo histological type, and 13 patients with histological grade III.

Only one patient (2.5\%) had a complication associated with sentinel node surgery, related to a seroma that was treated with drainage in the outpatient clinic. Regarding primary tumor surgery, four patients presented seroma, two of them associated with superficial surgical site infection (SSI).

$80 \%$ (34) of patients received adjuvant treatment: $27.5 \%(n=11)$ of them received chemotherapy because they have an infiltrating tumor in the final pathology report; $42.5 \%(n=17)$ radiotherapy and $67.5 \%(n=27)$ hormone therapy.

With a 49-month follow-up, only one patient presented local recurrence; this was a patient with comedotype DCIS, without the presence of an infiltrating tumor, a pathology report with a near margin that did not 
allow the second surgery for margin clearance. None of the patients in the series had an axillary or distant recurrence.

\section{Discussion}

DCIS is a lesion confined to the breast ducts without invading the adjacent stroma, reason why these lesions incompletely express the characteristics of invasive cancer, therefore making the SLNB technique to be currently restricted to precise indications, which include: tumor size greater than $3 \mathrm{~cm}$, patients undergoing mastectomy, biopsy report with a comedo-type lesion, and high histological grade. However, there is still controversy as to whether it should always be performed or restricted to the already described indications.

All patients in our study had one or more of these indications. 100\% of sentinel lymph nodes were found by using the lymphoscintigraphy and dual technique, and a $10 \%(n=4)$ positivity of the sentinel node. This is similar to what Price et al. in USA reported, who found positivity for SLNB in $10.4 \%$ of patients undergoing mastectomy plus SLN, and to what Al-Ameer et al. in Saudi Arabia reported, who obtained positivity in two out of 20 patients, which amounts to $10 \%$ of the study population [16,17]. Van Roozendaal et al. in the Netherlands also reported $9.3 \%$ sentinel node positivity, with $3.8 \%$ positivity with isolated cells, $3 \%$ micrometastasis, and $2.5 \%$ macrometastasis, results similar to those of our study [10].

Regarding the sentinel node positivity rates in Latin American countries, we find similarities in an experience by Ruvalcaba et al. in Mexico, who report positivity of $8 \%(n=4)$; however, it is striking that they mainly used the dual technique (lymphoscintigraphy + patent blue) in $82 \%$ of the cases in their study, as opposed to our experience, in which the sentinel node was identified in $95 \%$ of cases by lymphoscintigraphy, and only $5 \%$ by using the dual technique [18].

We found notable differences in terms of results in the Italian experience led by Intra (2003), where 223 patients with DCIS underwent SLNB, obtaining a positivity of only $3.1 \%$; this may be due to the fact that all SLNBs in this study were performed at the same surgical time of the primary tumor, while in the study by Intra et al, performance was delayed in $14.8 \%$ of cases until a pathology report of the primary tumor was obtained; another reason for this discrepancy may be the entire sample [8]. We also found differences with the experience by Heymans et al. who reported 3.1\% positivity of the sentinel node, probably due to the fact that they performed SLNB only in $66.7 \%$ of patients diagnosed with DCIS [9]. And in a Venezuelan experience, where they did not find positivity for SLNB in any patient, despite having a total of 64 patients with a diagnosis of DCIS and a sentinel node identification rate of $95.3 \%$; the study population had the infiltrating component underestimated because they used a vacuum cutting system to diagnose the primary tumor [19]. However, it must be clarified that these values are within the ranges reported in the literature, which range between $1 \%$ and $15 \%$.

The sentinel node procedure has gained strength for axillary staging in recent decades, as it represents a reduction in the risk of complications, which translates into better postoperative evolution and better quality of life for patients.

Numerous studies have compared the morbidity associated with the sentinel node procedure vs axillary lymph node dissection (ALND).; in the NSABP B-32 study, the authors found differences in morbidity associated with a three-year follow-up, favoring SLNB in the following aspects: deficit in shoulder abduction $>10 \%$ (41\% SLNB vs $75 \%$ ALND); lymphedema > 10\% ( $8 \%$ SLNB vs $14 \%$ ALND); sensitivity alteration in the inner face of the arm (23\% SLNB vs $49 \%$ ALND) [20]. In the prospective study by Langer in 2007, with a population of 651 patients, they found statistically significant differences in terms of morbidity in favor of the sentinel node $(35.8 \%$ vs $66.2 \%$. P $=<0.0001$ ), unlike the NSABP B32; in this study, they also reported immediate postoperative complications such as seroma $1.8 \%$, hematoma $1.8 \%$, and wound infection $0.9 \%$, complications that we studied in this report, finding only one patient with a seroma associated with the SLNB procedure [21].

DCIS locoregional relapse has been reported in $32.4 \%$ of patients managed with breast-conserving surgery, and in $12.6 \%$ in patients undergoing breast-conserving surgery plus radiotherapy with 84 months follow-up; relapse percentages are directly related to the presence of associated infiltrating carcinoma and to the positivity of the edges reported in the definitive pathological anatomy, which is associated with identification of residual DCIS in $40 \%$ to $82 \%$ of resection samples, correlating with margin width: $41 \%$ at $<1$ $\mathrm{mm}, 31 \%$ at $1-2 \mathrm{~mm}$, and $0 \%$ with $\geqslant 2 \mathrm{~mm}$ clearance [22].

In this study, with 49 months of follow-up, only one patient presented local recurrence, with the particularity that it was a comedo-type tumor, without the presence of an infiltrating tumor and with a near border, which did not allow the margin to be expanded. This discrepancy in the percentages can be explained by the shorter follow-up time in our study compared to the studies reported in the literature, but it corroborates the higher probability of relapse in cases with positive borders.

The main limitations of our work are those inherent to a retrospective study of a single institution. 


\section{Conclusions}

In this cohort, the high histological grade, the presence of comedo necrosis and palpable tumors were related to metastasis of the sentinel node in patients with DCIS. For these reasons, the SLNB in DCIS should be limited to patients with risk factors for infiltration (tumor size greater than $3 \mathrm{~cm}$, architectural pattern comedo necrosis, and high grade), and in patients with indication for mastectomy. This procedure has a low percentage of complications and a high percentage of identification in surgical groups with proper training.

\section{Additional Information \\ Disclosures}

Human subjects: Consent was obtained or waived by all participants in this study. COMITÉ DE ÉTICA EN INVESTIGACIONES DEL INSTITUTO NACIONAL DE CANCEROLOGÍA issued approval R00819-20. All procedures performed in studies involving human participants were in accordance with the ethical standards of the institutional and/or national research committee and with The Code of Ethics of the World Medical Association (Declaration of Helsinki). Animal subjects: All authors have confirmed that this study did not involve animal subjects or tissue. Conflicts of interest: In compliance with the ICMJE uniform disclosure form, all authors declare the following: Payment/services info: All authors have declared that no financial support was received from any organization for the submitted work. Financial relationships: All authors have declared that they have no financial relationships at present or within the previous three years with any organizations that might have an interest in the submitted work. Other relationships: All authors have declared that there are no other relationships or activities that could appear to have influenced the submitted work.

\section{References}

1. Global cancer observatory: International Agency for Research on Cancer . (2020). Accessed: December 20, 2020: https://gco.iarc.fr/today/fact-sheets-cancers.

2. Cutuli B: Ductal carcinoma in situ in 2019: diagnosis, treatment, prognosis [Article in French] . Presse Med. 2019, 48:1112-2. 10.1016/j.lpm.2019.08.018

3. Hanahan D, Weinberg RA: Hallmarks of cancer: the next generation . Cell. 2011, 144:646-74. 10.1016/j.cell.2011.02.013

4. Boughey JC, Gonzalez RJ, Bonner E, Kuerer HM: Current treatment and clinical trial developments for ductal carcinoma in situ of the breast. Oncologist. 2007, 12:1276-87. 10.1634/theoncologist.12-11-1276

5. Allred DC: Ductal carcinoma in situ: terminology, classification, and natural history . J Natl Cancer Inst Monogr. 2010, 2010:134-8. 10.1093/jncimonographs/lgq035

6. Brennan ME, Turner RM, Ciatto S, Marinovich ML, French JR, Macaskill P, Houssami N: Ductal carcinoma in situ at core-needle biopsy: meta-analysis of underestimation and predictors of invasive breast cancer. Radiology. 2011, 260:119-28. 10.1148/radiol.11102368

7. Fleissig A, Fallowfield LJ, Langridge CI, et al.: Post-operative arm morbidity and quality of life. Results of the ALMANAC randomised trial comparing sentinel node biopsy with standard axillary treatment in the management of patients with early breast cancer. Breast Cancer Res Treat. 2006, 95:279-93. 10.1007/s10549-005-9025-7

8. Intra M, Veronesi P, Mazzarol G, et al.: Axillary sentinel lymph node biopsy in patients with pure ductal carcinoma in situ of the breast. Arch Surg. 2003, 138:309-13. 10.1001/archsurg.138.3.309

9. Heymans C, van Bastelaar J, Visschers RGJ, Vissers YLJ: Sentinel node procedure obsolete in lumpectomy for ductal carcinoma in situ. Clin Breast Cancer. 2017, 17:e87-93. 10.1016/j.clbc.2016.10.002

10. van Roozendaal LM, Goorts B, Klinkert M, et al.: Sentinel lymph node biopsy can be omitted in DCIS patients treated with breast conserving therapy. Breast Cancer Res Treat. 2016, 156:517-25. 10.1007/s10549-016-3783-2

11. Lyman GH, Temin S, Edge SB, et al.: Sentinel lymph node biopsy for patients with early-stage breast cancer: American Society of Clinical Oncology clinical practice guideline update. J Clin Oncol. 2014, 32:1365-83. 10.1200/JCO.2013.54.1177

12. NCCN: Clinical Practice Guidelines in Oncology-Breast Cancer Version 4 . (2020). Accessed: December 20, 2020: http://www.nccn.com.

13. Miller ME, Kyrillos A, Yao K, Kantor O, Tseng J, Winchester DJ, Shulman LN: Utilization of axillary surgery for patients with ductal carcinoma in situ: a report from the National Cancer Data Base. Ann Surg Oncol. 2016, 23:3337-46. 10.1245/s10434-016-5322-0

14. El Hage Chehade H, Headon H, Wazir U, Abtar H, Kasem A, Mokbel K: Is sentinel lymph node biopsy indicated in patients with a diagnosis of ductal carcinoma in situ? A systematic literature review and metaanalysis. Am J Surg. 2017, 213:171-80. 10.1016/j.amjsurg.2016.04.019

15. Hung P, Wang SY, Killelea BK, Mougalian SS, Evans SB, Sedghi T, Gross CP: Long-term outcomes of sentinel lymph node biopsy for ductal carcinoma in situ. JNCI Cancer Spectr. 2019, 3:pkz052. 10.1093/jncics/pkz052

16. Price A, Schnabel F, Chun J, et al.: Sentinel lymph node positivity in patients undergoing mastectomies for ductal carcinoma in situ (DCIS). Breast J. 2020, 26:931-6. 10.1111/tbj.13737

17. Al-Ameer AY, Al Nefaie S, Al Johani B, et al.: Sentinel lymph node biopsy in clinically detected ductal carcinoma in situ. World J Clin Oncol. 2016, 7:258-64. 10.5306/wjco.v7.i2.258

18. Ruvalcaba-Limón E, de Jesús Garduño-Raya M, Bautista-Piña V, Trejo-Martínez C, Maffuz-Aziz A, Rodríguez-Cuevas S: Sentinel lymph node metastasis in patients with ductal breast carcinoma in situ [Article on Spanish]. Cir Cir. 2014, 82:129-41.

19. Acosta-Marín V, Acosta-Freites V, Ramírez AK, et al.: Utility of sentinel lymph node biopsy in ductal carcinoma in situ diagnosed with a vacuum-assisted core biopsy [Article on Spanish]. Rev Senol Patol 


\section{Cureus}

Mamar. 2017, 30:15-20. 10.1016/i.senol.2017.01.001

20. Ashikaga T, Krag DN, Land SR, et al.: Morbidity results from the NSABP B-32 trial comparing sentinel lymph node dissection versus axillary dissection. J Surg Oncol. 2010, 102:111-8. 10.1002/jso.21535

21. Langer I, Guller U, Berclaz G, et al.: Morbidity of sentinel lymph node biopsy (SLN) alone versus SLN and completion axillary lymph node dissection after breast cancer surgery: a prospective Swiss multicenter study on 659 patients. Ann Surg. 2007, 245:452-61. 10.1097/01.sla.0000245472.47748.ec

22. Patani N, Khaled Y, Al Reefy S, Mokbel K: Ductal carcinoma in-situ: an update for clinical practice . Surg Oncol. 2011, 20:e23-31. 10.1016/j.suronc.2010.08.007 